\title{
Green tea polyphenol (-)-epigallocatechin gallate suppressed the differentiation of murine osteoblastic MC3T3-E1 cell
}

\author{
M. Kamon ${ }^{\text {a }}$, R. Zhao ${ }^{\text {a }}$, and K. Sakamoto ${ }^{\mathrm{a}, *}$ \\ Graduate School of Life and Environmental Sciences, University of Tsukuba, Tsukuba, Ibaraki, \\ 305-8572 Japan \\ * Corresponding author. Tel.: +81 29853 4676; fax: +81 298534676

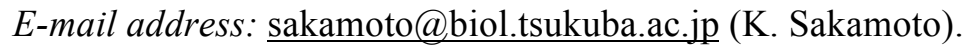

Keywords: Osteoblast, Catechin, Polyphenol, 


\begin{abstract}
Recently, various physiological effects of the tea polyphenol catechin for improving diseases such as cancer, arteriosclerosis, hyperlipedimia, and osteoporosis have been reported. However, the physiological effect of catechin on bone metabolism remains unclear. We examined the physiological effect of (-)-epigallocatechin-3-gallate (EGCG), which is the main component of green tea catechin, on osteoblast development using the precursor cell line of osteoblasts, MC3T3-E1, and co-culture of the osteoblasts from mouse newborn calvaria and mouse bone marrow cells. Although EGCG did not affect the viability and proliferation of MC3T3-E1, EGCG inhibited the osteoblast differentiation. Furthermore, EGCG did not affect the mineralization of differentiated MC3T3-E1, and reduced osteoclast formation in co-culture. These results suggest that EGCG can effectively suppress bone resorption, and can be used as an effective medicine for the symptoms of osteoporosis.
\end{abstract}




\section{INTRODUCTION}

Recently, various physiological effects of the tea polyphenol catechin for improving diseases such as cancer, arteriosclerosis, hyperlipemia, and osteoporosis have been reported (McKay and Blumberg, 2002; Crespy and Williamson, 2004). Green tea contains catechins such as (-)-epigallocatechin-3-gallate (EGCG), (-)-epicatechin-3-gallate (ECG), (-)-epicatechin (EC) and (-)-epigallocatechin (EGC), with EGCG accounting for more than $50 \%$ of the total of catechins (Nagle et al., 2006). In mammals, EGCG has the effect of improving lifestyle-related diseases such as tumor, allergy and arteriosclerosis (McKay and Blumberg, 2002; Crespy and Williamson, 2004). EGCG has various physiological functions such as the protection of DNA damage/methylation, suppression of protease activity, induction of apoptosis, and regulation of cell cycle and arrest, in the cell (Khan et al., 2006; Chen et al., 2008). Generally, although EGCG has strong anti-oxidant activity, it is difficult to explain the various physiological functions of catechin only by the anti-oxidization activity. Recently, Tachibana et al. (2004) reported that EGCG acted on a specific signaling pathway through binding to the $67 \mathrm{kDa}$ laminin receptor (67LR).

Tea polyphenol is known to mitigate osteoporosis as one of its physiological roles (Hegarty et al., 2000). Osteoporosis is caused by, for example, an imbalance of bone metabolism induced by the promotion of bone resorption due to a lack of estrogen during menopause (Saika et al., 2001). Usually, the amount of bone remains constant, as osteoblast-induced bone formation is balanced by bone resorption by osteoclasts, and the number and function of osteoclasts and osteoblasts are kept normal by the mutual interaction of these cells (Takahashi et al., 1988a; Jimi et al., 1996). For example, osteoblasts produce the colony stimulating factor-1 (CSF-1) and the differentiation-inducing factor, receptor activator of nuclear factor $\kappa B$ ligand (RANKL), and they act on the precursor of osteoclasts to promote the differentiation of osteoclast (Yoshida et al., 1990; Amano et al., 1998; Lacey et al., 1998; Yasuda et al., 1998). Moreover, the activated vitamin $\mathrm{D}_{3}\left(1,25(\mathrm{OH})_{2} \mathrm{D}_{3}\right)$, prostaglandin $\mathrm{E}_{2}$ and the parathyroid hormone act on osteoblasts, and control the differentiation of osteoclasts through the expression of RANKL (Takahashi et al., 1988a; Suda et al., 1999). On the other hand, osteoblasts differentiate from the mesenchymal stem cell under the stimulation of bone morphogenetic protein (BMP) (Katagiri and Takahashi, 2002). A 
mesenchymal stem cell may potentially differentiate into osteoblast, muscle cell or adipocyte. The differentiation of osteoblasts is led by the induction of expression of alkaline phosphatase (ALP) or bone matrix proteins such as type I collagen, osteocalcin $(\mathrm{OCN})$ and osteopontin, under the action of the transcription factors runt-related transcription factor 2 (Runx2) and Osterix (Nakashima et al., 2002; Komori, 2005). Furthermore, the repression of the differentiation factor to muscle cell and adipocyte also leads to the differentiation to osteoblasts (Nakashima et al., 2002; Komori, 2005).

To date, little has been known about the physiological role of EGCG, except the induction of osteoclast cell death (Nakagawa et al., 2002; Yun et al., 2007) and mineralization of osteoblasts (Takita et al., 2002; Vali et al., 2007). This report aims to elucidate the physiological role and molecular mechanism of tea catechin on bone metabolism.

\section{MATERIALS AND METHODS}

\subsection{Expression plasmid}

The expression plasmid (pGEX-2TK-RANKL) for the soluble RANKL-GST fusion protein was a gift from Dr. Takeya at the University of Nara Institute of Science and Technology (Meiyanto et al., 2001; Ishida et al., 2002).

\subsection{Cell culture}

MC3T3-E1 cells (RIKEN Institute of Physical and Chemical Research cell bank, Tsukuba, Ibaraki, Japan) were cultured at $37^{\circ} \mathrm{C}$ in $100-\mathrm{mm}$ dishes in Minimum Essential Medium Alpha Medium ( $\alpha$-MEM) (Invitrogen, Carlsbad, CA, USA) containing $50 \mathrm{mg} / \mathrm{L}$ ascorbic acid, supplemented with 10\% FBS (Sanko Junyaku, Chiyoda, Tokyo, Japan). MC3T3-E1 cells were spread at density of $3.2 \times 10^{4}$ cells $/ \mathrm{cm}^{2}$ in $\alpha$-MEM (10\% FBS) containing EGCG (Mitsui Nourin Co., Ltd., Minato, Tokyo, Japan), ECG (Mitsui Nourin), resveratrol (Wako Pure Chemical, Osaka, Japan), or N-Acetylcysteine (Sigma-Aldrich, St. Louis, MO, USA).

We obtained bone marrow cells from femurs and tibiae of 6-week-old male mouse and osteoblasts from mouse newborn calvaria (Saitama Experimental Animal Supply, Katsushika, Saitama, Japan). Bone marrow cells and osteoblasts were spread in the 
same plate with $\alpha$-MEM (10\% FBS) at density of $2 \times 10^{5}$ cells/well and $2 \times 10^{4}$ cells/well, respectively (co-culture). To stimulate the differentiation of osteoclast, these cells were cultured simultaneously on the same plate for $6 \mathrm{~d}$ under the stimulation of

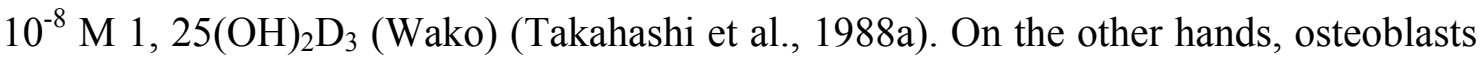
were cultured solely for $6 \mathrm{~d}$ with $10^{-8} \mathrm{M} 1,25(\mathrm{OH})_{2} \mathrm{D}_{3}$, and bone marrow cells were cultured solely for $6 \mathrm{~d}$ with $100 \mathrm{ng} / \mathrm{ml}$ RANKL and $20 \mathrm{ng} / \mathrm{ml} \mathrm{CSF-1} \mathrm{(PeproTech} \mathrm{Inc.,}$ Rocky Hill, NJ, USA).

RAW264 cells (RIKEN) were cultured at $37^{\circ} \mathrm{C}$ in $100-\mathrm{mm}$ dishes in Dulbecco's modified Eagle's medium (DMEM) (Sigma-Aldrich) supplemented with 10\% FBS and 1\% MEM non-essential amino acid solution (NEAA) (Invitrogen). To induce osteoclast development, RAW264 cells were plated on a 96-well plate at $2 \times 10^{3}$ cells/well and cultured in $\alpha$-MEM (10\% FBS, $1 \%$ NEAA) containing $100 \mathrm{ng} / \mathrm{mL}$ RANKL for $5 \mathrm{~d}$.

\subsection{ALP staining}

After the culture, cells were incubated with $100 \mu \mathrm{L}$ of $4 \%$ paraformaldehyde at $4{ }^{\circ} \mathrm{C}$ for $1 \mathrm{~h}$. Each well was washed with distilled water, and then $100 \mu \mathrm{L}$ of ALP stain solution (100 mM Tris-HCl [pH 8.4], 0.01\% naphthol AS-MX phosphate [Sigma-Aldrich], $0.06 \%$ fast blue BB salt [Sigma-Aldrich]) was added to each well and incubated for $30 \mathrm{~min}$ (Chang et al., 2003). Cells were washed with distilled water and observed under an optical microscope.

\subsection{ALP activity assay}

After the culture, cells were washed with PBS. The enzyme activity of ALP was measured by directly adding $100 \mu \mathrm{L} /$ well of ALP-assay-buffer $(0.6 \mathrm{M}$ diethanolamine, $0.6 \mathrm{mM} \mathrm{MgCl}_{2}, 0.1 \%$ Triton X-100, and $30 \mathrm{mM}$-nitrophenylphosphate) to each well. After the incubation for $15 \mathrm{~min}$ at room temperature, the reaction was terminated by adding $50 \mu \mathrm{L} /$ well of $3 \mathrm{M} \mathrm{NaOH}$, and the absorbance was measured at $405 \mathrm{~nm}$ using microplate reader (Kodaira et al., 2006). The ALP activity was normalized to its protein concentration and represented as units per microgram of protein, with each unit of activity being defined as the amount of enzyme that produces $1 \mathrm{nmol}$ $p$-nitrophenol/min.

\subsection{Cell viability and proliferation}


Dead cells were stained with trypan blue. MC3T3-E1 cells were cultured on 40-mm dishes for $48 \mathrm{~h}$. Then, the culture medium was replaced with new medium containing EGCG and cultured for additional $48 \mathrm{~h}$. After the culture, cells were washed with PBS, and then incubated with $1 \mathrm{~mL}$ of $0.25 \%$ trypan blue solution for $1 \mathrm{~min}$. Cells were washed with PBS and observed under an optical microscope.

Cell viability was determined by 3-(4, 5-dimethyl thiazol-2-yl)-2, 5-diphenyl tetrazolium bromide (MTT) assay. MC3T3-E1 cells were plated on a 96-well plate at 2 $\times 10^{3}$ cells/well and cultured for $48 \mathrm{~h}$. Then, the culture medium was replaced with new medium containing EGCG and cultured for additional $48 \mathrm{~h}$. After the culture, cells were washed with PBS, MTT was added and incubated for additional $3 \mathrm{~h}$. The product was dissolved in $0.04 \mathrm{~N} \mathrm{HCl}$ in isopropanol, and the absorbance at $570 \mathrm{~nm}$ was measured.

Cell proliferation was analyzed by using BrdU Cell Proliferation Assay Kit (Merck, Whitehouse Station, NJ, USA). MC3T3-E1 cells were cultured with EGCG for $24 \mathrm{~h}$. Then, cells were incubated with BrdU for additional $6 \mathrm{~h}$, and the absorbance at 450-540 nm was measured.

\subsection{PCR analysis}

Cells were cultured on $40-\mathrm{mm}$ dishes, and the total RNA was extracted by a standard acid-GTC-phenol extraction method (Chomczynski and Sacchi, 1987). The cDNA was synthesized by M-MLV Reverse Transcriptase (Takara Bio, Otsu, Shiga, Japan), and subjected for PCR using the following primers:

G3PDH primers:

G3PDH-S1 (5'-GACCCTTCATTGACCT-3')

G3PDH-A1 (5'-CCACCACCCTGTTGCTGT-3')

Osteocalcin (OCN) primers:

mOCN-S1 (5'-AGTCCCACACAGCAGCTT-3')

mOCN-A1 (5'-AGCCGAGCTGCCAGAGTT-3')

Alkaline phosphatase (ALP) primers:

mALP-S1 (5'-AGGGTGGACTACCTCTTA-3')

mALP-A1 (5'-GCCTGGTAGTTGTTGTGA-3')

Receptor activator of nuclear factor $\kappa \mathrm{B}$ ligand (RANKL) primers:

mRANKL-S1 (5'-GACATGTGCCACTGAGAA-3')

mRANKL-A1 (5'- TGACAAGTCTGAAGACTC-3') 
Colony stimulating factor-1 (CSF-1) primers:

mCSF1-S3 (5'- TCCTGCAGCAGTTGATCG-3')

mCSF1-A3 (5'- GCTGTTGTTGCAGTTCTTGG-3')

PCR was performed using following conditions; for G3PDH primers $\left(95{ }^{\circ} \mathrm{C}\right.$ for 5 min; 18 or 19 cycles of $95{ }^{\circ} \mathrm{C}$ for $30 \mathrm{~s}, 55^{\circ} \mathrm{C}$ for $1 \mathrm{~min}, 72{ }^{\circ} \mathrm{C}$ for $1 \mathrm{~min} ; 72{ }^{\circ} \mathrm{C}$ for 7 min), for other primers $\left(94{ }^{\circ} \mathrm{C}\right.$ for $5 \mathrm{~min} ; 25-33$ cycles of $94{ }^{\circ} \mathrm{C}$ for $30 \mathrm{~s}, 59^{\circ} \mathrm{C}$ for $30 \mathrm{~s}$, $72{ }^{\circ} \mathrm{C}$ for $30 \mathrm{~s} ; 72{ }^{\circ} \mathrm{C}$ for $\left.7 \mathrm{~min}\right)$.

\subsection{Mineralization assay}

MC3T3-E1 cells were cultured for $10 \mathrm{~d}$. Then, the culture medium was replaced with new medium containing $10 \mathrm{mM} \beta$-glycerophosphate and cultured for additional 10 d. After the culture, cells were washed with PBS, and fixed with $70 \% \mathrm{EtOH}$ for $1 \mathrm{~h}$ at room temperature. Cells were washed with distilled water, and $100 \mu \mathrm{L}$ of $1 \%$ Alizarin Red S solution (Kanto Chemical Co., Inc.) was added to each well and incubated. After 30 min incubation, cells were washed with distilled water. Then, the dye was dissolved in $100 \mu \mathrm{L}$ of $100 \mathrm{mM}$ cetylpyridinium, and absorbance was measured at $562 \mathrm{~nm}$ (Wang et al., 2007).

\subsection{TRAP staining}

Cells were washed with PBS, and cells were fixed by incubation with $100 \mu \mathrm{L}$ of $4 \%$ paraformaldehyde at $4{ }^{\circ} \mathrm{C}$ for $1 \mathrm{~h}$. Each well was washed with distilled water, and then incubated with $100 \mu \mathrm{L}$ of tartrate-resistant acid phosphatase (TRAP) solution (50 $\mathrm{mM}$ sodium tartrate, $45 \mathrm{mM}$ sodium acetate $[\mathrm{pH} 5.0], 0.01 \%$ naphthol AS-MX phosphate [Sigma-Aldrich], $0.03 \%$ fast red violet LB salt [Sigma-Aldrich]) for $10 \mathrm{~min}$ (Matsumoto et al., 2000). Cells were washed with water and observed under an optical microscope.

\subsection{Statistical analysis}

Results are expressed as mean \pm standard deviation. Comparisons between groups were made by analysis of variance (ANOVA), and when significant, were examined by Tukey's all-pairwise-comparison test. Differences were considered significant when $P<$ 0.05. Statistical analysis was performed using Excel 2004 (Microsoft, Redmond, WA, USA) with the add-in software Statcal 2 (Yanai, 2004). 


\section{RESULTS}

\subsection{Effect of EGCG on differentiation of MC3T3-E1 cells}

MC3T3-E1 cells originally derived from mouse calvaria were used to investigate the physiological role of EGCG on the differentiation of osteoblasts (Kodama et al., 1981). MC3T3-E1 cells were cultured in a medium containing the green tea catechin EGCG, ECG, red grape polyphenol resveratrol, or N-acetylcysteine for $10 \mathrm{~d}$. The dyeing analysis of the ALP-positive cells by the ALP stain method revealed that the number of ALP-positive cells decreased by the stimulation of $10 \mu \mathrm{M}$ EGCG and $10 \mu \mathrm{M}$ ECG (Fig. 1A). On the other hand, there was almost no change in the cells treated with $10 \mu \mathrm{M}$ resveratrol. The ALP activity was reduced by the addition of EGCG and ECG, whereas resveratrol did not affect ALP activity (Fig. 1B (a)). Furthermore, $10 \mathrm{mM}$ $\mathrm{N}$-acetylcysteine, which has anti-oxidant activity, increased ALP activity (Fig. 1B (b)).

Next, MC3T3-E1 cells were cultured in the presence of EGCG $(0,1,2.5,5$, or 10 $\mu \mathrm{M}$ ) for $4 \mathrm{~d}, 7 \mathrm{~d}$, and $10 \mathrm{~d}$, and the ALP activity was measured. As shown in Figure 2A, EGCG reduced the ALP activity dose-dependently: $10 \mu \mathrm{M}$ EGCG suppressed ALP activity to about $50 \%$ of the control. The influence of EGCG on the expression of osteoblast-specific gene was analyzed by RT-PCR. Both expressions of ALP and OCN decreased as a result of the addition of EGCG (Fig. 2B). These results revealed that tea catechin, especially EGCG, suppressed the differentiation of MC3T3-E1 cells.

\subsection{EGCG does not change the viability and proliferation of MC3T3-E1 cells}

Next, the effects of catechin (EGCG) on the viability or proliferation of MC3T3-E1 cells were analyzed. First, the dead cells were dyed by trypan blue. Although trypan blue dyed most of the cells that had been treated by $100 \mathrm{mM} \mathrm{H}_{2} \mathrm{O}_{2}$, the trypan blue-positive cells were hardly detected under the treatment by $10 \mu \mathrm{M}$ EGCG (Fig. 3A). Next, MC3T3-E1 cells were cultured in the medium containing EGCG $(0,1,5,10,15$, or $20 \mu \mathrm{M}$ ), and cell viability was analyzed by MTT assay. The MTT is converted into formazan by mitochondrial dehydrogenase in the viable cells. Measureing the absorbence of the dissolved formazan enables the calculation of the survival rate. As a result, EGCG (up to $20 \mu \mathrm{M}$ ) did not influence the survival rate of the cells (Fig. 3B). To determine the physiological effect of EGCG on cell proliferation, the BrdU proliferation 
assay was performed. The BrdU proliferation assay involves incorporation of BrdU into newly synthesized DNA strands of actively proliferating cells. Following partial denaturation of double stranded DNA, BrdU is detected immunochemically allowing the assessment of the population of cells which are actively synthesizing DNA. As shown in Fig. 3C, EGCG $(0,1,2.5,5$, or $10 \mu \mathrm{M})$ did not change the incorporation of BrdU into MC3T3-E1 cells at all. These data suggested that EGCG specifically suppressed cell differentiation of osteoblasts without affecting cell proliferation or cell death.

\subsection{Effect of EGCG on physiological function of differentiated MC3T3-E1 cells}

Next, the physiological function of EGCG on differentiated osteoblasts was analyzed. MC3T3-E1 cells were cultured for $10 \mathrm{~d}$ to induce differentiation, then the differentiated cells were cultured for a further $10 \mathrm{~d}$ with $\operatorname{EGCG}(0,1,2.5$, 5, or $10 \mu \mathrm{M})$. ALP analysis revealed that EGCG treatment had no effect on ALP activity in the differentiated cells at all (Fig. 4A). Next, the effect of EGCG on mineralization by osteoblasts was analyzed. The MC3T3-E1 cells cultured for $10 \mathrm{~d}$ were incubated for a further $10 \mathrm{~d}$ with $10 \mathrm{mM} \quad \beta$-glycerophosphate and $10 \mu \mathrm{M}$ EGCG to induce mineralization. Analysis by the Alizarine Red S stain method clarified that EGCG had no effect at all on mineralization in the differentiated MC3T3-E1 cells (Fig. 4B). These data do not contradict the result that EGCG had no influence on the cell proliferation and survival rate of MC3T3-E1 cells. The results suggested that EGCG did not affect ALP activity or mineralization in the differentiated osteoblasts.

\subsection{Effect of EGCG on osteoclast formation in co-cultured cells}

It is well known that osteoblasts induce the differentiation of osteoclasts through the production of RANKL and CSF-1 (Katagiri and Takahashi, 2002). Therefore, the influence of EGCG on the ability of osteoblasts to induce differentiation was analyzed by using co-culture of osteoblasts and the precursor of osteoclasts. The osteoblasts collected from the calvaria of mouse newborn and bone marrow cells collected from mouse tibia and femur were cultured simultaneously on the same plate under the stimulation of $1,25(\mathrm{OH})_{2} \mathrm{D}_{3}$ to stimulate the differentiation of osteoclasts. The expression of TRAP is specific to osteoclasts. The dyeing analysis of the TRAP-positive cells by the TRAP-stain method was performed. The number of 
differentiated osteoclasts decreased by the treatment of $10 \mu \mathrm{M}$ EGCG (Fig. 5A), and EGCG suppressed the formation of osteoclasts from the bone marrow cells cultured solely in the presence of RANKL and CSF-1 (Fig. 5A). So, we analyzed whether EGCG affects the induction of osteoclast differentiation through the action of osteoblasts. RT-PCR analysis of RANKL and CSF-1 in osteoblasts revealed that EGCG did not change the expression of RANKL or CSF-1 (Fig. 5B). In addition, RAW264 cells were cultured in the medium containing EGCG $(0,1,2.5,5$, or $10 \mu \mathrm{M})$ and 100 $\mathrm{ng} / \mathrm{mL}$ RANKL for $5 \mathrm{~d}$. EGCG remarkably suppressed the formation of osteoclasts from RAW264 cells, too (Fig. 6A), and the number of osteoclasts was decreased by EGCG treatment (Fig. 6B). These results suggested that EGCG suppressed the development of osteoclasts in co-cultured cells, possibly through direct action on osteoclast precursor cells.

\section{DISCUSSION}

It has been reported some polyphenols have physiological actions on the regulation of bone metabolism. For example, red wine polyphenols, such as resveratrol and piceatannol, promoted the differentiation of osteoblasts and so on (Mizutani et al., 1998; Chang et al., 2006), and resveratrol and EGCG led to the cell death of osteoclasts (Nakagawa et al., 2002; Boissy et al., 2005; Yun et al., 2007). It is well known that these physiological actions are caused partially by the anti-oxidative effect of polyphenol, however, the molecular mechanism of these effects is not well understood.

Therefore, we analyzed the physiological effects of EGCG on the differentiation of osteoblasts by using a precursor cell line of osteoblasts, MC3T3-E1, which was originally derived from mouse calvaria (Kodama et al., 1981). ALP activation decreased remarkably when tea catechin EGCG or ECG was added to the culture of MC3T3-E1 (Fig. 1). EGCG suppressed the expression of mRNA of ALP and OCN which are specifically expressed in osteoblasts (Fig. 2B). On the other hand, because resveratrol did not reduce ALP activity at all (Fig. 1), it is suggested that osteoblast differentiation is suppressed by tea catechin specifically. Moreover, the anti-oxidant $\mathrm{N}$-acetylcysteine increased ALP activity (Fig. 1B (b)). It was also reported that $\mathrm{N}$-acetylcysteine promotes the differentiation of osteoblasts (Jun et al., 2008), and therefore EGCG may 
be involved in osteoblast differentiation by a mechanism other than its anti-oxidative action. Recently, Tachibana et al. (2004) reported that EGCG acted on the specific signaling pathway through binding to the $67 \mathrm{kDa}$ laminin receptor. The signaling pathway of 67LR is known little, however, it is thought that extracellular signal-regulated kinase and myosin regulatory light chain possibly be involved in (Fujiwara et al., 2005; Umeda et al., 2005). Therefore, further investigation is necessary to analyze whether this laminin receptor is actually involved in the signal transduction of EGCG in osteoblasts. EGCG influenced neither the cell death of MC3T3-E1 nor cell survival rate (Figs. 3A, B). Since EGCG affected cell proliferation much less (Fig. 3C), it is possible that EGCG influences the differentiation of osteoblasts directly.

Next, the effect of EGCG on the bone formation of osteoblasts was analyzed to clarify the role of EGCG in the function of osteoblasts. As a result, EGCG had no effect on ALP activity in the differentiated MC3T3-E1 cell (Fig. 4A). This result suggests that EGCG did not affect the enzymatic activity of ALP itself, either. Furthermore, the addition of EGCG to the differentiated MC3T3-E1 cell did not influence mineralization (Fig. 4B). These results suggest that EGCG has a suppressive effect on differentiation to the precursor cell of osteoblasts, although EGCG has little effect on differentiated osteoblasts. The osteoblasts lead to the differentiation of osteoclasts through the production of RANKL. The formation of osteoclasts was decreased by the addition of EGCG when the osteoblasts from the mouse calvaria and the mouse bone marrow cell were co-cultured (Fig. 5A). When EGCG was added to the single-culture of bone marrow cells, the number of osteoclasts decreased (Fig. 5A) and the mRNA expression of RANKL and CSF-1 was not changed (Fig. 5B), so it is possible that EGCG acts on the precursor of osteoclasts directly, resulting in the suppression of differentiation. In order to know the direct action of EGCG on osteoclast development, mouse RAW264, an osteoclast differentiation-inducible cell line, was used for analysis. The mouse RAW264, a macrophage-like monocyte cell line, can develop into osteoclast-like multi-nuclear cells under the stimulation of RANKL (Matsumoto et al., 2000; Ralph and Nakoinz, 1977). EGCG suppressed the osteoclast formation of RAW264 cells, too (Fig. 6). There are also reports that EGCG promotes the cell death of osteoclast cell lines (Nakagawa et al., 2002; Yun et al., 2007), suggesting that EGCG may promote cell death of osteoclasts or their precursor directly, thus reducing the number of osteoclasts.

Judging from the previous data (Nakagawa et al., 2002; Yun et al., 2007), EGCG 
possibly acts on osteoclasts or their precursor cell directly, and suppresses the differentiation of osteoclasts. Furthermore, because EGCG suppressed the differentiation of osteoblasts, it is thought that EGCG restrains the number of osteoclasts by suppressing the new formation of osteoblasts, in vivo. Of course, the concentration of EGCG in the blood is critically important to know the physiological role of EGCG in living animals. So far, it has been reported that the concentration of EGCG rises to about $10 \mu \mathrm{M}$ in the blood when a high dose EGCG is administered orally (Ullmann et al., 2003). In this study, we applied less than $10 \mu \mathrm{M}$ of EGCG, suggesting a condition which is close to that of the living body. This indicates that EGCG can be used as an effective medicine against the symptoms of osteoporosis.

\section{ACKNOWLEDGEMENTS}

This work was supported in part by Grants-in-Aid for Scientific Research from the Ministry of Education, Science, Sports, and Culture of Japan.

We wish to thank Dr. Tatsuya Takeya (Nara Institute of Science and Technology, Graduate School of Biological Sciences) for providing expression plasmid of RANKL-GST. We are also grateful to Dr. Hitoshi Amano (School of Dentistry, Showa University) for technical supporting. We wish to thank Mitsui Norin Co., Ltd. for providing catechin compounds.

\section{REFERENCES}

Amano H, Yamada S, Felix R. Colony-stimulating factor-1 stimulates the fusion process in osteoclasts. J Bone Miner Res 1998; 13: 846-53.

Boissy P, Andersen TL, Abdallah BM, et al. Resveratrol inhibits myeloma cell growth, prevents osteoclast formation, and promotes osteoblast differentiation. Cancer Res 2005; 65: 9943-52. 
Chang JK, Hsu YL, Teng IC, et al. Piceatannol stimulates osteoblast differentiation that may be mediated by increased bone morphogenetic protein-2 production. Eur J Pharmacol 2006; 551: 1-9.

Chen D, Milacic V, Chen MS et al. Tea polyphenols, their biological effects and potential molecular targets. Histol Histopathol 2008; 23: 487-96.

Chomczynski P, Sacchi N. Single-step method of RNA isolation by acid guanidinium thiocyanate-phenol-chloroform extraction. Anal Biochem 1987; 162: 156-9.

Crespy V and Williamson G. A review of the health effects of green tea catechins in in vivo animal models. J Nutr 2004; 134: 3431S-40S.

Fujiwara Y, Yamada K, Tachibana H. A lipid raft-associated $67 \mathrm{kDa}$ laminin receptor mediates suppressive effect of epigallocatechin-3-O-gallate on FcepsilonRI expression. Biochem Biophys Res Commun 2005; 336: 674-81.

Hegarty VM, May HM, Khaw KT. Tea drinking and bone mineral density in older women. Am J Clin Nutr 2000; 71: 1003-7.

Ishida N, Hayashi K, Hoshijima M, et al. Large scale gene expression analysis of osteoclastogenesis in vitro and elucidation of NFAT2 as a key regulator. J Biol Chem 2002; 277: 41147-56.

Jimi E, Nakamura I, Amano H, et al. Osteoclast function is activated by osteoblastic cells through a mechanism involving cell-to-cell contact. Endocrinology 1996; 137: 2187-90.

Jun JH, Lee SH, Kwak HB, et al. N-acetylcysteine stimulates osteoblastic differentiation of mouse calvarial cells. J Cell Biochem 2008; 103: 1246-55.

Katagiri T, Takahashi N. Regulatory mechanisms of osteoblast and osteoclast differentiation. Oral Dis 2002; 8: 147-59. 
Khan N, Afaq F, Saleem M, et al. Targeting multiple signaling pathways by green tea polyphenol (-)-epigallocatechin-3-gallate. Cancer Res 2006; 66: 2500-5.

Kodama H, Amagai Y, Sudo S, et al. Establishment of aclonal osteogenic cell line from newborn mouse calvaria. Jpn J Oral Biol 1981; 23: 899-901.

Kodaira K, Imada M, Goto M, et al. Purification and identification of a BMP-like factor from bovine serum. Biochem Biophys Res Commun 2006; 345: 1224-31.

Komori T. Regulation of skeletal development by the Runx family of transcription factors. J Cell Biochem 2005; 95: 445-53.

Lacey DL, Timms E, Tan HL, et al. Osteoprotegerin ligand is a cytokine that regulates osteoclast differentiation and activation. Cell 1998; 93: 165-76.

Matsumoto M, Sudo T, Maruyama M, et al. Activation of p38 mitogen-activated protein kinase is crucial in osteoclastogenesis induced by tumor necrosis factor. FEBS Lett 2000; 486: 23-8.

McKay DL, Blumberg JB. The role of tea in human health: an update. J Am Coll Nutr 2002; 21: 1-13.

Meiyanto E, Hoshijima M, Ogawa T, et al. Osteoclast differentiation factor modulates cell cycle machinery and causes a delay in s phase progression in RAW264 cells. Biochem Biophys Res Commun 2001; 282: 278-83.

Mizutani K, Ikeda K, Kawai Y, et al. Resveratrol stimulates the proliferation and differentiation of osteoblastic MC3T3-E1 cells. Biochem Biophys Res Commun 1998; 253: 859-63.

Nagal DG, Ferreira D, Zhou YD. Epigallocatechin-3-gallate (EGCG): chemical and biomedical perspectives. Phytochemistry 2006; 67: 1849-55. 
Nakagawa H, Wachi M, Woo JT, et al. Fenton reaction is primarily involved in a mechanism of (-)-epigallocatechin-3-gallate to induce osteoclastic cell death. Biochem Biophys Res Commun 2002; 292: 94-101.

Nakashima K, Zhou X, Kunkel G, et al. The novel zinc finger-containing transcription factor osterix is required for osteoblast differentiation and bone formation. Cell 2002; 108: 17-29.

Ralph P, Nakoinz, I. Antibody-dependent killing of erythrocyte and tumor targets by macrophage-related cell lines: enhancement by PPD and LPS. J Immunol 1977; 119: 950-4.

Saika M, Inoue D, Kido S, Matsumoto T. 17 beta-estradiol stimulates expression of osteoprotegerin by a mouse stromal cell line, ST-2, via estrogen receptor-alpha. Endocrinology 2001; 142: 2205-12.

Suda T, Takahashi N, Udagawa N, et al. Modulation of osteoclast differentiation and function by the new members of the tumor necrosis factor receptor and ligand families. Endocr Rev 1999; 20: 345-57.

Tachibana H, Koga K, Fujimura Y, et al. A receptor for green tea polyphenol EGCG. Nat Struct Mol Biol 2004; 11: 380-1.

Takahashi N, Akatsu T, Udagawa N, et al. Osteoblastic cells are involved in osteoclast formation. Endocrinology 1988a; 123: 2600-2.

Takita H, Kikuchi M, Sato Y, et al. Inhibition of BMP-induced ectopic bone formation by an antiangiogenic agent (epigallocatechin 3-gallate). Connect Tissue Res 2002; 43: 520-3.

Ullmann U, Haller J, Decourt JP, et al. A single ascending dose study of epigallocatechin gallate in healthy volunteers. J Int Med Res 2003; 31: 88-101. 
Umeda D, Tachibana H, Yamada K. Epigallocatechin-3-O-gallate disrupts stress fibers and the contractile ring by reducing myosin regulatory light chain phosphorylation mediated through the target molecule $67 \mathrm{kDa}$ laminin receptor. Biochem Biophys Res Commun 2005; 333: 628-35.

Vali H, Rao LG, El-Sohemy A. Epigallocatechin-3-gallate increases the formation of mineralized bone nodules by human osteoblast-like cells. J Nutr Biochem 2007; 18: $341-7$.

Wang J, Shang F, Jiang R, et al. Nitric oxide-donating genistein prodrug: design, synthesis, and bioactivity on MC3T3-E1 cells. J Pharmacol Sci 2007; 104: 82-9.

Yanai H. Statcel-The useful add-in software forms on Excel (2nd ed). Saitama (Japan): OMS, 2004.

Yasuda H, Shima N, Nakagawa N, et al. Osteoclast differentiation factor is a ligand for osteoprotegerin/osteoclastogenesis-inhibitory factor and is identical to TRANCE/RANKL. Proc Natl Acad Sci USA 1998; 95: 3597-602.

Yoshida H, Hayashi S, Kunisada T, et al. The murine mutation osteopetrosis is in the coding region of the macrophage colony stimulating factor gene. Nature 1990; 345: 442-4.

Yun JH, Kim CS, Cho KS, et al. (-)-Epigallocatechin gallate induces apoptosis, via caspase activation, in osteoclasts differentiated from RAW 264.7 cells. J Periodontal Res 2007; 42: 212-8.

\section{FIGURE LEGENDS}

Fig. 1. Effect of polyphenols on osteoblast differentiation. MC3T3-E1 cells were cultured in the presence of $10 \mu \mathrm{M}$ EGCG, $10 \mu \mathrm{M}$ ECG, $10 \mu \mathrm{M}$ resveratrol (Res) or 10 
mM N-Acetylcysteine (NAC) for $10 \mathrm{~d}$. (A) After the culture, cells were fixed by $4 \%$ paraformaldehyde solution and stained by ALP method. (B) Cells were incubated with ALP assay buffer and ALP enzyme activity was measured. An error bar shows standard error of the mean, $n=5$. Against a value of (-), ** indicates $P<0.01$.

Fig. 2. Effect of EGCG on osteoblast differentiation. (A) MC3T3-E1 cells were cultured in the presence of EGCG $(0,1,2.5,5$, or $10 \mu \mathrm{M})$ for 4,7 , or $10 \mathrm{~d}$, and ALP enzyme activity was measured. An error bar shows standard error of the mean, $n=5$. Against a value of $0 \mathrm{M}$ on each culture period, ** indicates $P<0.01$. (B) MC3T3-E1 cells were cultured in the presence of $0 \mathrm{M} \mathrm{(-)}$ or $10 \mu \mathrm{M}(+)$ EGCG for 1, 4, 7, or $10 \mathrm{~d}$. Total RNA was extracted and RT-PCR was performed with specific primers for ALP (33 cycle), OCN (25 cycle), or G3PDH (19 cycle).

Fig. 3. Effect of EGCG on cell viability and proliferation. (A) MC3T3-E1 cells were cultured for $48 \mathrm{~h}$. Then, the cells were cultured in the medium containing $0 \mathrm{M}$ or $10 \mu \mathrm{M}$ EGCG for $48 \mathrm{~h}$. As positive control, cells were treated with $100 \mathrm{mM} \mathrm{H}_{2} \mathrm{O}_{2}$ for $30 \mathrm{~min}$. After the culture, cells were stained by trypan blue method. ( $\times 400$ magnification, scale

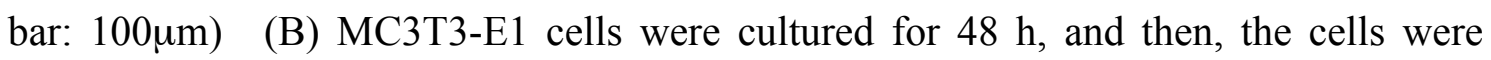
cultured additional $48 \mathrm{~h}$ in the medium containing $\operatorname{EGCG}(0,5,10,15$, or $20 \mu \mathrm{M})$. After the culture, cells were treated for MTT assay. The product was dissolved in $0.04 \mathrm{~N}$ $\mathrm{HCl} /$ isopropanol and absorbance at $570 \mathrm{~nm}$ was measured. Cell viability was calculated relative to value of $0 \mathrm{M}$. An error bar shows standard error of the mean, $n=6$. (C) MC3T3-E1 cells were cultured with EGCG $(0,1,2.5,5$, or $10 \mu \mathrm{M})$ for $24 \mathrm{~h}$. To analyze DNA synthesis, cells were incubated with BrdU for $6 \mathrm{~h}$. An error bar shows standard error of the mean, $n=6$.

Fig. 4. Effect of EGCG on differentiated osteoblasts. (A) MC3T3-E1 cells were cultured for $10 \mathrm{~d}$. Then, the cells were cultured in the medium containing EGCG (0, 1 , $2.5,5$, or $10 \mu \mathrm{M}$ ) for additional $10 \mathrm{~d}$. After the culture, the ALP enzyme activity was measured. An error bar shows standard error of the mean, $n=5$. (B) MC3T3-E1 cells were cultured for $10 \mathrm{~d}$. Then, the culture medium was replaced with new medium containing $0 \mathrm{M} \mathrm{(-)}$ or $10 \mu \mathrm{M}(+)$ EGCG and $10 \mathrm{mM} \beta$-glycerophosphate and cultured for additional $10 \mathrm{~d}$. After the culture, cells were stained by Alizarin Red S. An error bar 
shows standard error of the mean, $n=3$.

Fig. 5. Effect of EGCG on osteoclast formation in the co-cultured cells. (A) In the co-culture, mouse bone marrow cells $(\mathrm{BM})$ and osteoblasts $(\mathrm{OB})$ were cultured in the presence of $0 \mathrm{M} \mathrm{(-)}$ or $10 \mu \mathrm{M}(+)$ EGCG and $10^{-8} \mathrm{M} 1,25(\mathrm{OH})_{2} \mathrm{D}_{3}$ for $6 \mathrm{~d}$. In the OB culture, OB were cultured in the presence of $0 \mathrm{M} \mathrm{(-)}$ or $10 \mu \mathrm{M}(+)$ EGCG and $10^{-8} \mathrm{M} 1$, $25(\mathrm{OH})_{2} \mathrm{D}_{3}$ for $6 \mathrm{~d}$. In the $\mathrm{BM}$ culture, $\mathrm{BM}$ were cultured in the presence of $0 \mu \mathrm{M}(-)$ or $10 \mu \mathrm{M}(+)$ EGCG and $100 \mathrm{ng} / \mathrm{mL}$ RANKL and $20 \mathrm{ng} / \mathrm{mL} \mathrm{CSF-1} \mathrm{for} 6 \mathrm{~d}$. After the culture, cells were stained by TRAP method. TRAP-positive cells were observed $(\times 100$ magnification, scale bar: $500 \mu \mathrm{m})$. (B) Mouse osteoblast was cultured in the presence of $0 \mathrm{M}(-)$ or $10 \mu \mathrm{M}(+)$ EGCG and $10^{-8} \mathrm{M} 1,25(\mathrm{OH})_{2} \mathrm{D}_{3}$ for $1 \mathrm{~d}$. Total RNA was extracted and RT-PCR was performed with specific primers for RANKL (28 cycle), CSF-1 (25 cycle), and G3PDH (18 cycle).

Fig. 6. Effect of EGCG on osteoclast differentiation. (A) RAW264 cells were cultured in the presence of $0 \mu \mathrm{M}(-)$ or $10 \mu \mathrm{M}(+)$ EGCG and $100 \mathrm{ng} / \mathrm{mL}$ RANKL for $5 \mathrm{~d}$. After the culture, cells were stained by TRAP method. TRAP-positive cells were observed ( $\times 50$ magnification, scale bar: 1mm). (B) RAW264 cells were cultured in the presence of EGCG $(0,1,2.5,5$, or $10 \mu \mathrm{M})$ and $100 \mathrm{ng} / \mathrm{mL}$ RANKL for $5 \mathrm{~d}$. The number of TRAP-positive multi-nuclear cells (MNC) with more than three nuclei were measured (cells/well). An error bar shows standard deviation of the mean, $n=6$. Against a value of $0 \mathrm{M}, * P<0.05$ and $* * P<0.01$. 
Figure 1
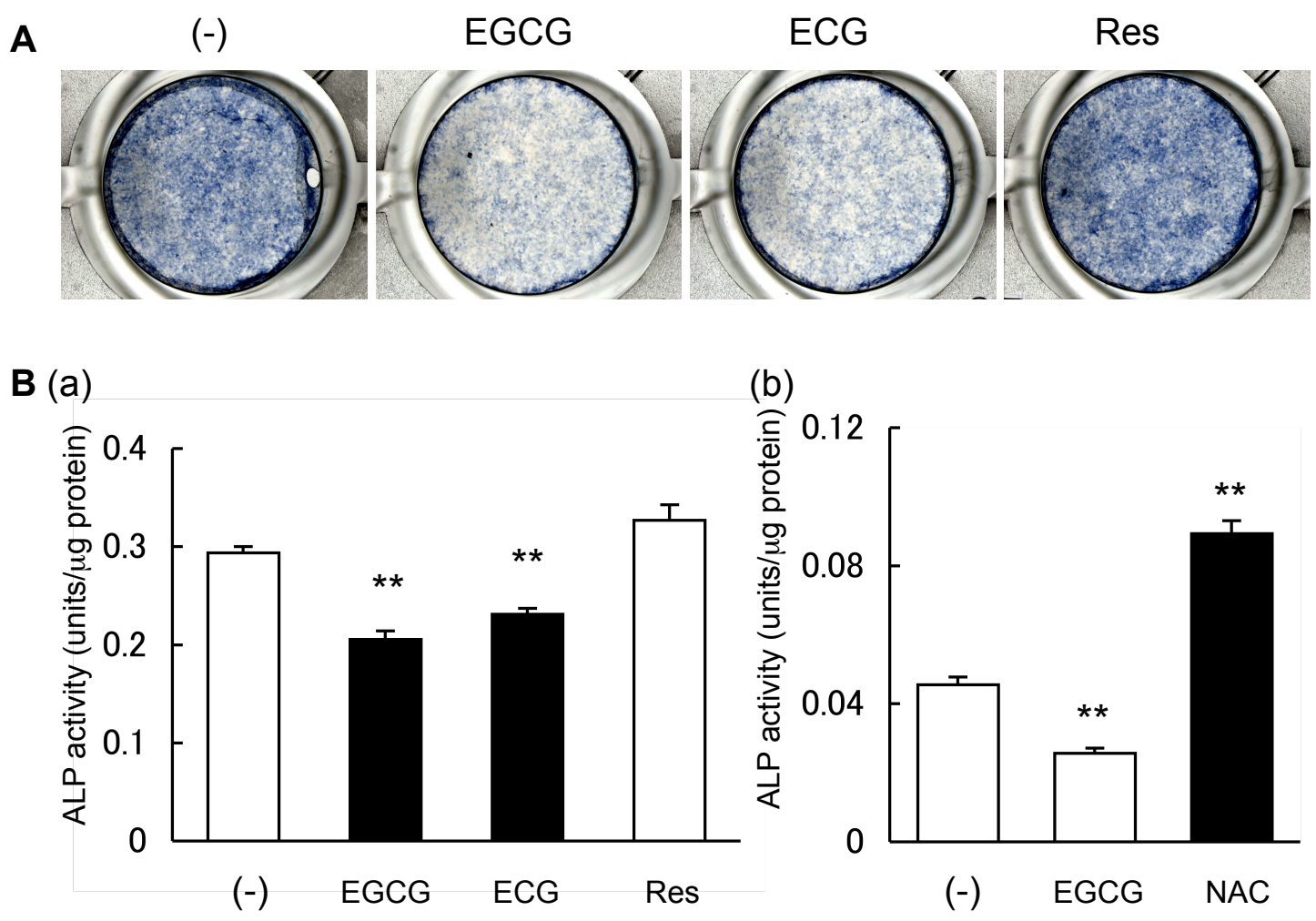

(b)

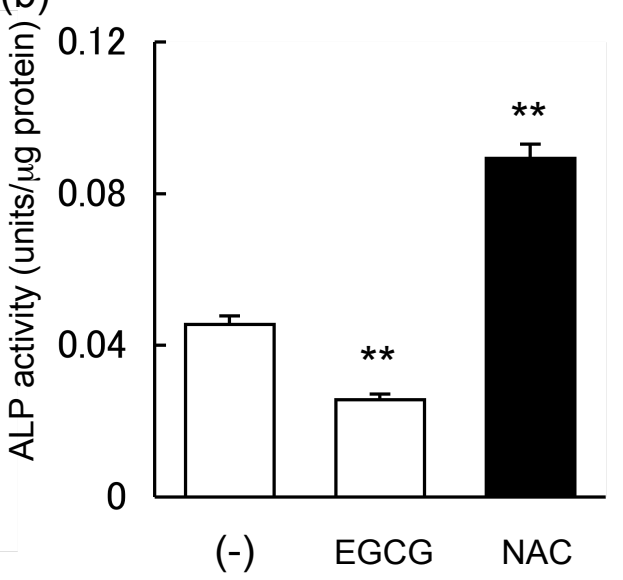


Figure 2

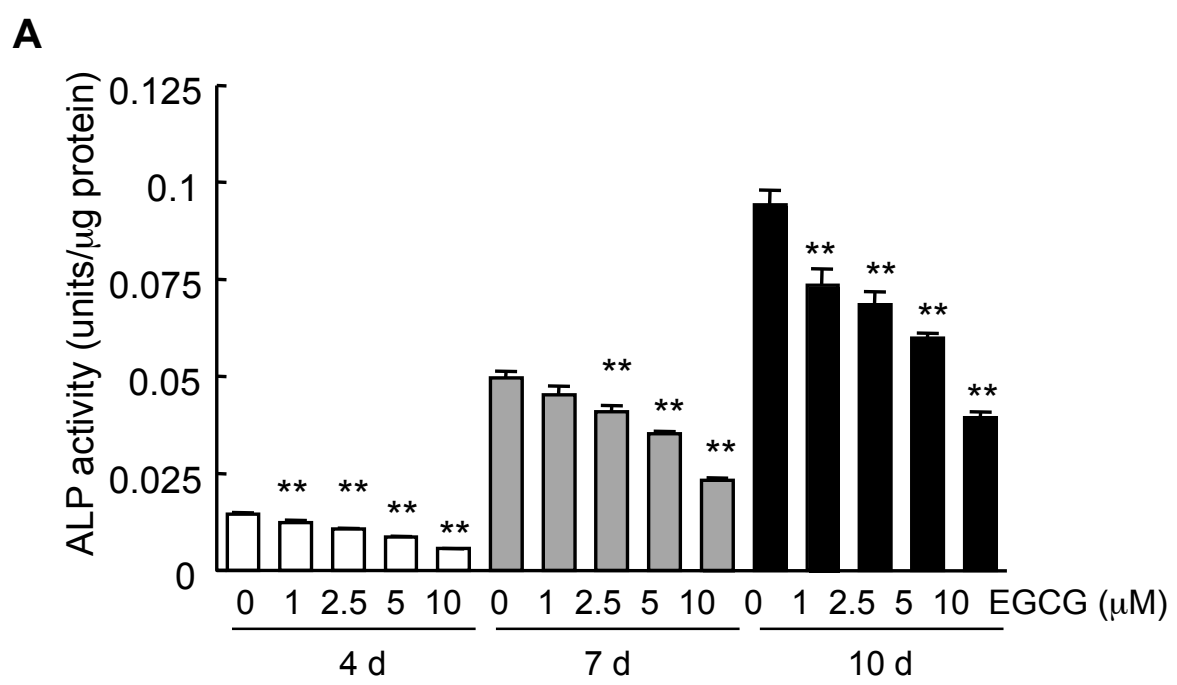

B

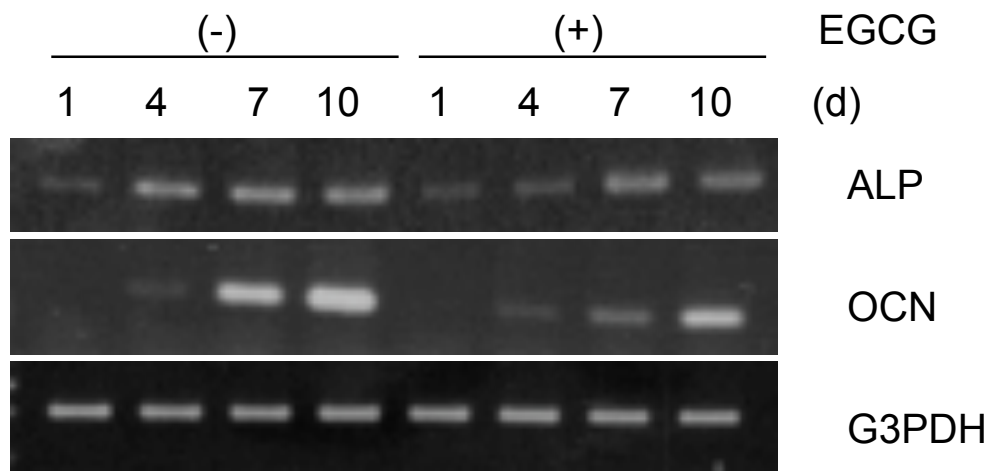


Figure 3

A

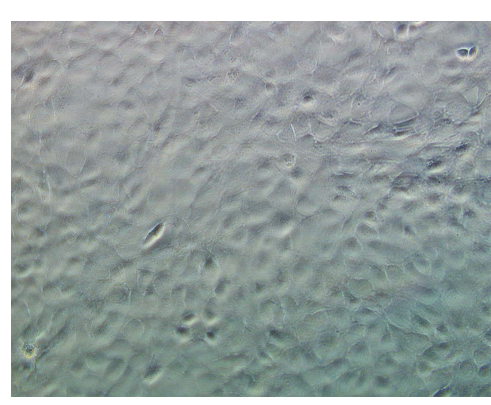

B

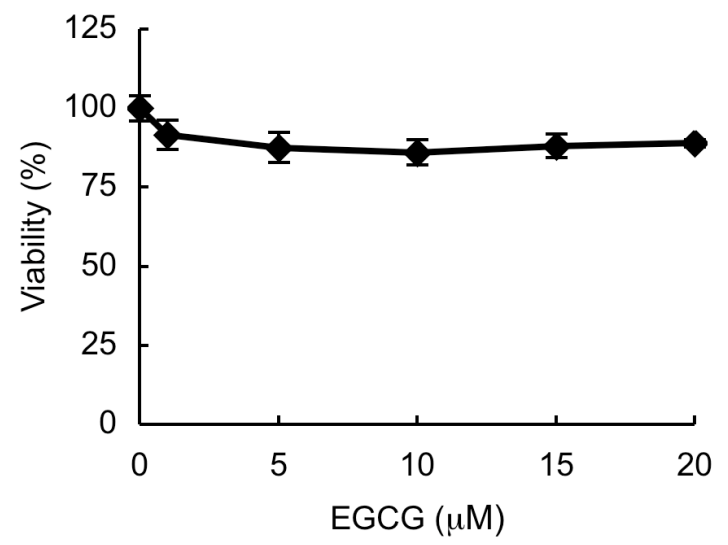

$(+)$
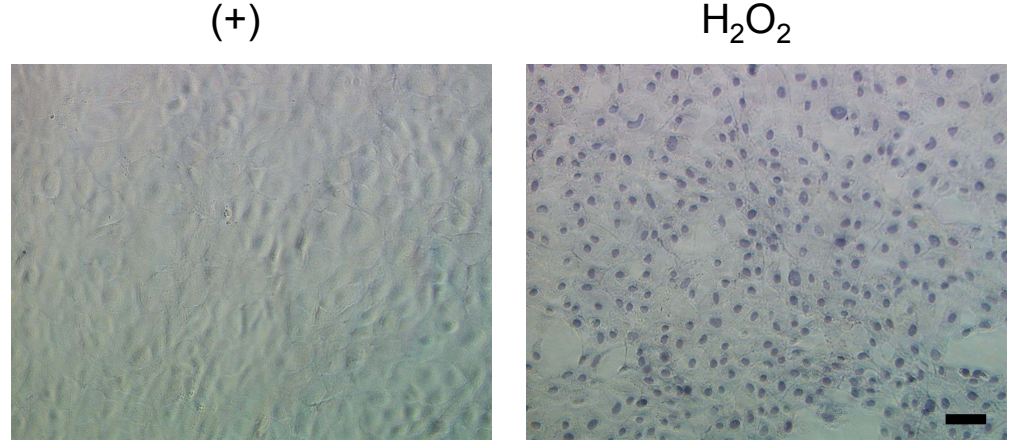

C

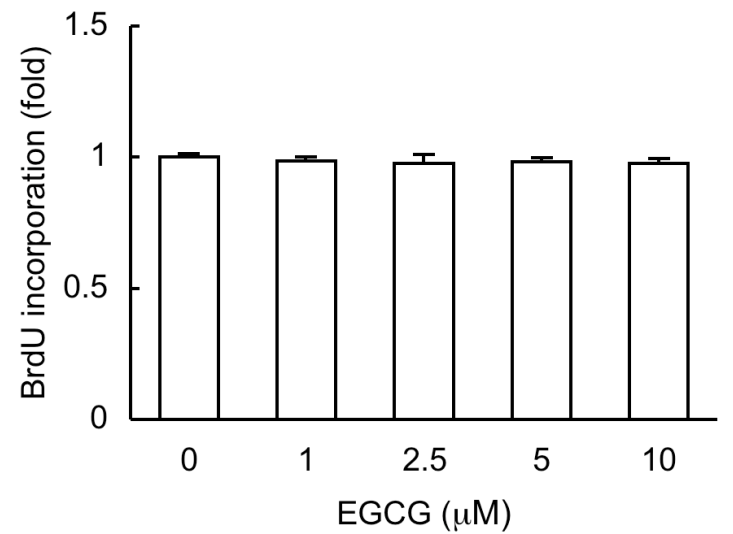


Figure 4

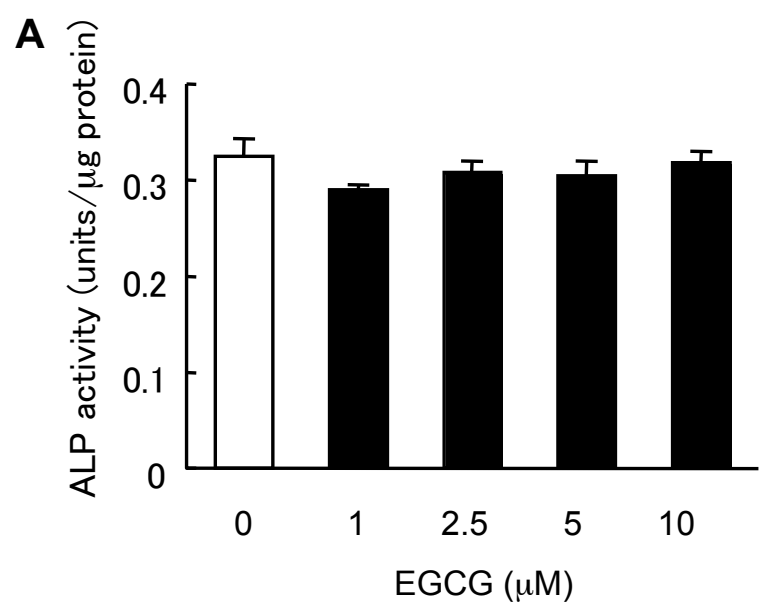

B

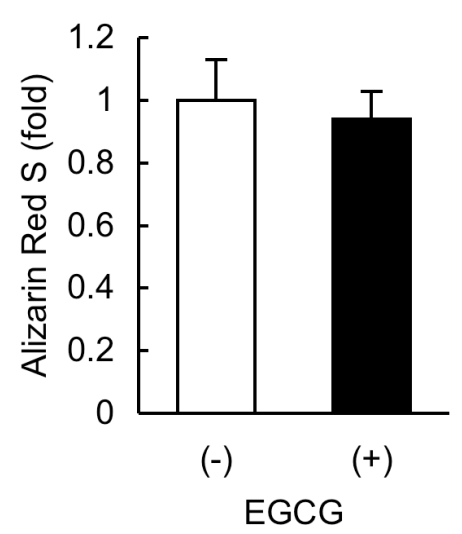


Figure 5

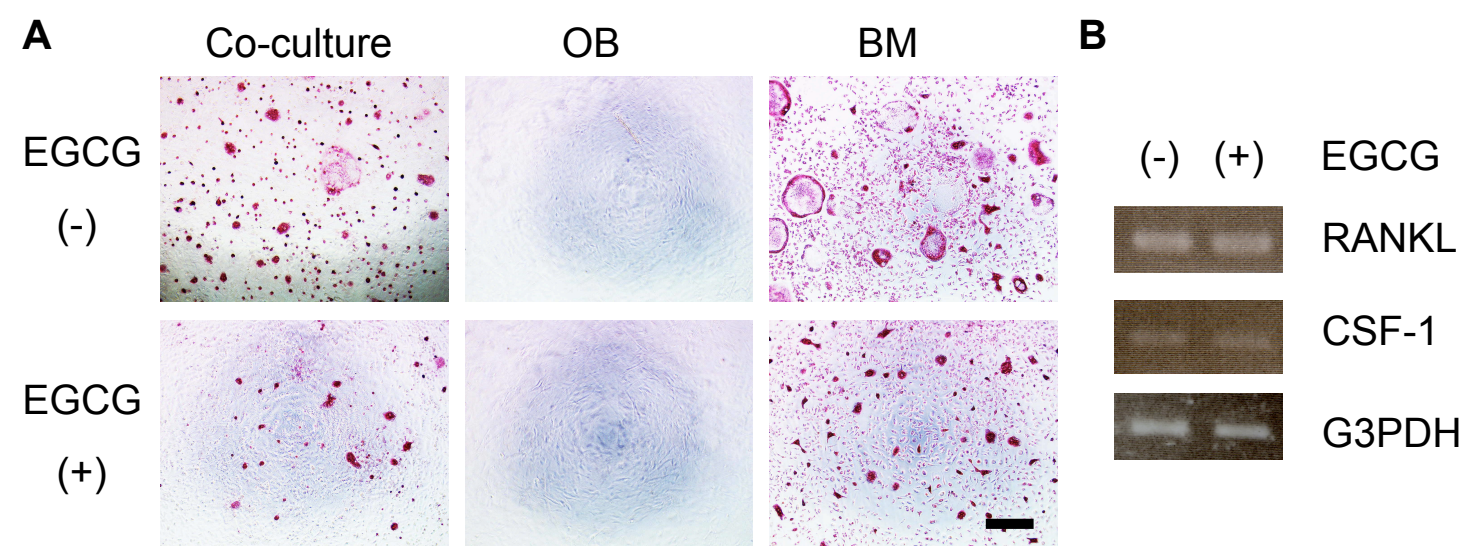


Figure 6

A EGCG (-)

$(+)$
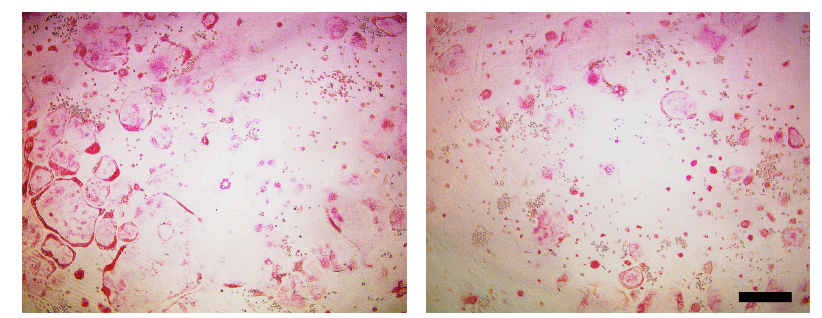

B

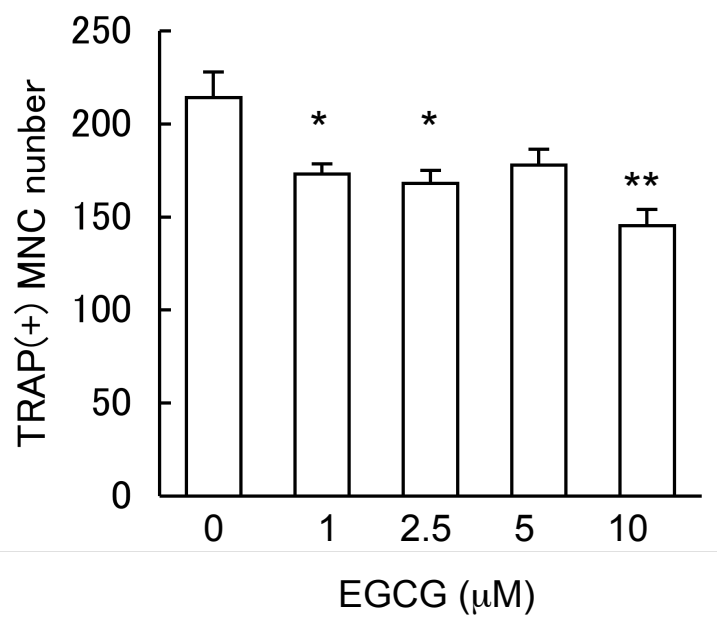

